\title{
A CIDADE-REGIÃO SOB AS COEXISTÊNCIAS DO TERRITÓRIO
}

\author{
THE CITY-REGION UNDER COEXISTENCE IN THE TERRITORY
}

\section{LA CIUDAD-REGIÓN BAJO LAS COEXISTENCIAS DEL TERRITORIO}

\author{
Josué Alencar Bezerra - Universidade do Estado do Rio Grande do Norte - \\ Pau dos Ferros - Rio Grande do Norte - Brasil \\ josueabezerra@gmail.com
}

\begin{abstract}
Resumo
Nas últimas décadas, a urbanização contemporânea tem proporcionado grandes transformações no território brasileiro, como o crescimento do número e tamanho das cidades e o representativo aumento dos papéis urbanos na divisão territorial do trabalho. Essas mudanças são evidenciadas pela nova lógica espacial das empresas industriais, pelas recentes estratégias de localização dos equipamentos comerciais e de serviços, como também pela atual configuração do habitat urbano em diversas escalas geográficas. Essa nova configuração do território coloca a cidade-região como uma unidade espacial a ser considerada para entender 0 atual sistema de cidades em suas múltiplas escalas, permitindo-nos pensar esse conceito no âmbito dos estudos urbano-regionais do território. Ao estudarmos a cidade-região devemos considerar, ainda, as lógicas integradas através do aumento dos fluxos de pessoas, mercadorias, insumos e informação no território, como configuração espacial materializada pelo processo de urbanização recente.

Palavras-chave: Cidade-região, urbanização, cidade, região.
\end{abstract}

\section{Abstract}

In the last decades, the contemporary urbanization has provided great transformations in the brazilian territory, as the growth of the number and size of the cities and the representative increase of the urban roles in the territorial division of labor. These changes are evidenced by the new spatial logic of the industrial companies, by the recent strategies of location of the commercial equipment and of services, as well as by the current configuration of the urban habitat in diverse geographic scales. This new configuration of the territory places the city-region as a spatial unit to be considered in order to understand the present system of cities in its multiple scales, allowing us to think this concept within the framework of the urban-regional studies of the territory. In studying the city-region, one must also consider the integrated logics by increasing the flows of people, goods, inputs and information in the territory, as a spatial configuration materialized by the recent urbanization process.

Keywords: City-region, urbanization, city, region.

\section{Resumen}

Durante las últimas décadas, la urbanización contemporánea ha proporcionado grandes transformaciones en el territorio brasileño, como el crecimiento del número y tamaño de las ciudades y el representativo aumento de los papeles urbanos en la división territorial del trabajo. Estos cambios son evidenciados por la nueva lógica espacial de las empresas industriales, por las recientes estrategias de localización de los equipamientos comerciales y de servicios, así como por la actual configuración del hábitat urbano en diversas escalas geográficas. Esta nueva configuración del territorio sitúa a la ciudad-región como una unidad espacial a ser considerada para entender el actual sistema de ciudades en sus múltiples escalas, permitiendo pensar ese concepto en el ámbito de los estudios urbano-regionales del territorio. Al estudiar la ciudad-región debemos considerar, incluso, las lógicas integradas a través del aumento del flujo de personas, mercancías, insumos e información en el territorio, como configuración espacial materializada por el proceso de urbanización reciente. Palabras-clave: Ciudad-región, urbanización, ciudad, región. 
Primeiras palavras: elementos para se pensar a cidade-região hoje

Desde a segunda metade do século passado, estamos vivenciando uma mudança qualitativa no processo geral da urbanização, que pode ser entendida pelas fortes transformações ocorridas em diversas escalas do urbano e da cidade, o que está ligado especialmente à revolução da informação, dos gostos e ao crescimento do consumo, rebatendo diretamente na produção destes espaços (Santos, 2005; Limonad, 2008b).

O meio técnico-científico-informacional (Santos, 2004, 2008), advindo da modernização recente no espaço, vem sendo difundido por todo lugar, inclusive nas periferias das grandes cidades, ou mesmo nas regiões mais afastadas dos aglomerados urbanos metropolitanos.

Com isso, observamos uma dissolução de grandes investimentos produtivos pelo território, de políticas públicas de Estado de diversas naturezas e, consequentemente, um aumento da população urbana, não apenas nas áreas mais desenvolvidas do território, onde se encontra a maioria das grandes cidades e centros metropolitanos. Desse modo, de acordo com Santos (2005, p. 138): "Estaríamos, agora, deixando a fase da mera urbanização da sociedade, para entrar em outra, na qual defrontamos a urbanização do território."

Sobre estas novas tendências da urbanização brasileira, os estudos em geografia, considerados sob a perspectiva da dinâmica urbana e regional, continuam privilegiando áreas onde estas mudanças dão-se de forma mais intensa nas grandes cidades, uma vez que tais espaços se mostram como reflexo latente destas transformações advindas da globalização da economia (Harvey, 2009).

Esse é um processo que possibilita o debate sobre a "desregionalização" do mundo, em função dos discursos da relativa homogeneização promovida pela mercantilização econômica e cultural, pois, de acordo com Haesbaert (2010), o que se vê é a acentuação de movimentos regionais localizados, pelo próprio fato de que a globalização alimenta-se da diferenciação ${ }^{1}$.

Na rede urbana ${ }^{2}$ brasileira, buscamos entender esse novo processo de urbanização que vem chegando nas regiões e nas cidades, ou melhor, apreender as cidades nas regiões, entre distintas escalas de análise que, segundo Limonad (2008b), também são reflexo de um processo intrinsecamente ligado à estruturação do território e que envolvem principalmente a distribuição espacial da população e das atividades econômicas de diversos setores. 
Sobre este tema, acompanhamos o debate das desigualdades regionais, especialmente em áreas de menor dinâmica urbana e regional, que tendem a permanecer à margem dos fluxos econômicos principais e apresentam menores níveis de renda e bem-estar da população, medidos comumente pelo Índice de Desenvolvimento Humano (IDH) e pelo Produto Interno Bruto (PIB)/Habitante.

Retrato disso são as várias políticas de desenvolvimento regional que ressurgiram em toda parte para mitigarem os efeitos negativos da globalização, como aquelas implementadas pelo Ministério da Integração Nacional (MIN, 2005), a partir do Plano Nacional de Desenvolvimento Regional (PNDR), que propõe estratégias para amenizar as desigualdades no âmbito das microrregiões brasileiras.

A partir dessas políticas de desenvolvimento regional realizadas nas últimas décadas, é possível constatar novas heterogeneidades e desigualdades acentuadas pela urbanização contemporânea, marcadas pelo acionamento do território por diversas forças produtivas, mediante as novas tecnologias, ferramentas, máquinas e toda uma infraestrutura providenciada pelo homem para extrair capital (Limonad, 2008b).

Desse modo, nossa inquietação sobre o atual momento da urbanização brasileira, processo que vem integrando cada vez mais o território a partir de sua estruturação, proporcionando o aparecimento de fenômenos urbanos, como a periurbanização, centralização e segregação urbana, evidencia a cidade-região como uma unidade espacial característica e que representa as mudanças recentes vistas no território brasileiro, que pode extrapolar o contexto metropolitano, devido à intensidade cada vez maior da mobilidade espacial da população e da dispersão urbana (Ojima; Marandola Jr., 2012).

Para alguns estudiosos (Klink, 2001; Scott et al., 2001b; Lencioni, 2006), a cidade-região seria uma unidade espacial polarizada e comandada por uma cidade que exerce influência sob uma grande área constituída por várias outras cidades menores. A cidade-região passa a ser definida a partir do processo de urbanização, tendo suas lógicas integradas através do aumento dos fluxos de pessoas, mercadorias, insumos e informação de forma centrípeta no território (Santos, 2005).

As cidades e suas respectivas regiões constituem um traço dessa nova urbanização brasileira, especialmente no que se refere às formas espaciais de ocupação urbana em áreas metropolitanas ou não. A leitura dessas regiões pode assumir algumas possibilidades de formato no âmbito 
urbano e regional (Moura, 2009), promovido, particularmente, pela reestruturação do território, em que os centros assumem um caráter de concentração regional, em uma situação geográfica privilegiada em relação aos grandes centros urbanos do país. Assim, a interlocução com alguns autores que tratam do fenômeno da cidade-região nos mostra a definição dos aportes teórico-metodológicos que orientam essa discussão que segue.

\section{Alguns estudos sobre a cidade-região}

Os estudos que remetem à discussão do conceito de cidaderegião estão associados às fases da urbanização até chegarmos à era da globalização, que resultou na intensificação e no barateamento dos meios de transporte e de comunicação localizados não só nos países mais ricos, mas também nos menos desenvolvidos (Lencioni, 2006; Harvey, 2009).

Esse modo de pensar se dá em face à emergência dos processos contemporâneos que imprimem os novos arranjos e dinâmicas visualizadas em diversas partes do território, os quais são identificados pela maior parte dos estudiosos que tratam estes espaços na visão econômica (Scott et al., 2001b) como sendo uma característica do processo de formação da cidade-região.

A importância de cada um dos trabalhos desenvolvidos sobre esse tema possibilita requalificar a escala espacial utilizada nos estudos urbano-regionais, porém, tendo sempre o cuidado com a dimensão e a realidade espaço-temporal que cada um propôs desenvolver.

No que tange o princípio da origem da terminologia cidade-região, não podemos deixar de destacar o papel do filósofo escocês Patrick Geddes, que se dedicou ao estudo das cidades nessa fase da urbanização (final do século XIX e começo dos anos 1910), dizendo que era necessário enxergá-las como uma extensão do habitante e reintegrar o homem no movimento do urbano ${ }^{3}$.

Geddes $(1915,1994)^{4}$ foi um dos primeiros a utilizar o termo cidaderegião, em seu livro Cidades em Evolução (Sarmento, 2004), publicado originalmente no início do século XX, quando estudou Londres e seu papel na constituição de uma grande região composta por vilas, cidades pequenas e cidades industriais, dando origem ao que ele inicialmente chamou de grandes cidades-região. Sarmento (2004, p. 13, grifo do autor) coloca que na visão de Geddes, "[...] a cidade-região tem um centro urbano claro, que se desenvolve radialmente em sua hinterland." 
As discussões realizadas por Geddes (1915), apesar de terem ocorrido há mais de um século, serviram como base para os primeiros estudos urbano-regionais no contexto da nova fase da urbanização conhecida pelo homem no decorrer do século passado (Sarmento, 2004).

John B. Parr, pesquisador da Universidade de Glasgow (Escócia), é um dos seguidores dessa leitura e se debruçou nas mudanças da urbanização e do papel das cidades-região também no contexto britânico (Parr, 2005). Em algumas de suas obras (Parr, 2005), ele se dedicou a investigar a imprecisão na identificação desses espaços no contexto atual da urbanização, diante da propalada globalização e da "sociedade em rede”, que promoveram novas mudanças na organização das cidades (Castells, 2005).

A princípio, tomando alguns conceitos clássicos da geografia, como o de região, Parr (2005) afirma que há uma confusão no entendimento sobre a região homogênea, a região nodal e a região política ${ }^{5}$, quando estudamos a cidade na atual fase da urbanização. Para isso, é preciso distinguir duas formas de região: a cidade-região e a região urbana policêntrica.

Parr (2005) traçou a importância da cidade-região como característica fundamental na organização espacial na dimensão territorial de um país. Segundo o autor, tem ocorrido um crescimento no interesse do estudo desses espaços, porém, voltado às estruturas zonais e interações espaciais (Corrêa, 2006) vinculadas às atividades comerciais, à mobilidade espacial da população (principalmente pendular) e ao movimento de capitais que se apresentam como variáveis indispensáveis para a conformação da cidade-região.

Na revista Urban Studies ${ }^{6}$, encontramos o trabalho de Coombes (2014), que trata do caso de Londres, e a difícil missão de definir os limites da cidade-região a partir das questões político-administrativas em pauta naquele território. Este é um desafio de cidades que se encontram em uma área de divisa com outros estados, o que dificulta a adoção de uma regionalização mais aproximada da dimensão territorial de sua cidaderegião. Coombes (2014) discorre ainda sobre a importância das ocupações rurais na leitura da cidade-região, pois estas ajudam a definir a organização das cidades e a dimensão territorial da cidade-região.

As áreas temáticas, específicas a cada porção do território, podem ser utilizadas como referência na dimensão da cidade-região. No trabalho de Kanai (2014), a formação da cidade-região de Manaus é tratada a partir do espaço guiado pelo Estado sob o empreendimento ecológico. As áreas de 
preservação e a disposição de uma rede urbana dendrítica são comandadas por uma metrópole fincada no meio da Amazônia brasileira.

Isso posto, partimos da premissa de estudar o contexto urbanoregional em que a cidade primaz utiliza de outros fixos na estruturação da rede urbana (Sposito, 2011; Santos, 2004).

Com a leitura sobre cidade-região, podemos dizer que sua discussão se confunde com as experiências dos geógrafos originários da escola californiana, Allen Scott, John Agnew, Michael Storper e Edward Soja que, há algum tempo, estudam a globalização nas perspectivas política, cultural e econômica, observando a organização do espaço da região Sul da Califórnia, porção do território norte-americano que vem sofrendo grandes transformações nas últimas décadas, região mais densamente povoada e tecnologicamente mais desenvolvida dos Estados Unidos (Scott et al., 2001a, 2001b). Para estes estudiosos, a cidade-região surge como uma unidade socioespacial que dá conta de examinar os fluxos socioeconômicos cada vez mais dinâmicos verificados no território (Scott et al., 2001b).

Soja (1993) indica que a cidade-região passa a ser a forma urbana mais completa do processo de urbanização na contemporaneidade. Resguardando as realidades de cada território, estes espaços apresentam rupturas e continuidades com o processo de formação das próprias cidades e regiões e que, para capturar o sentido dessas, é preciso entender melhor a natureza desse fenômeno.

Em uma reflexão mais recente, Soja (2013, p. 150) aponta que:

A literatura urbana dominante ainda não reconheceu este modelo regional de urbanização de forma explícita, mas há sinais de que a transformação da urbanização metropolitana para a regional e o uso de termos associados tais como cidades-região e cidades regionais crescerão em importância para a análise geográfica urbana ao longo da próxima década.

Quando levantamos a produção sobre o tema no contexto brasileiro, temos como um dos principais nomes o da professora Sandra Lencioni (Geografia/USP). Em alguns trabalhos (Lencioni, 2004, 2006), a autora realiza a discussão considerando a relação local, regional e global a partir da perspectiva das redes geográficas contemporâneas, analisando suas dinâmicas ligadas à reestruturação do território.

Tendo como principal objeto de estudo a metrópole paulistana, Lencioni (2004) considera o papel das redes geográficas de fundamental 
importância para o entendimento da cidade-região, no que se refere à relação direta e indireta da reprodução do capital. Em grande parte de sua obra, a autora analisa os processos de produção do espaço urbano-regional a partir da reestruturação produtiva ligada à indústria.

Em um ensaio que fez exercitando o conceito de cidade-região, Lencioni (2006) incita que a globalização e as adequações econômicas recentes das forças produtivas vêm impulsionando mudanças nas redes geográficas, especialmente nas urbanas, o que proporcionou uma multiplicidade e espraiamento das atividades no território. As redes expressam "[...] as relações de circulação do capital e é nessa expressão que evidenciamos uma das dimensões do espaço: o espaço como meio, ou seja, o espaço como mediação necessária à reprodução do capital em escala globalizada” (Lencioni, 2006, p. 66). Apesar da autora estar se referindo à produção em um espaço global, em estágio avançado da urbanização, sua argumentação abrange toda a linha que aponta as redes definidoras dessa produção e que se dá na relação entre a forma global de se organizar a rede de fluxos que alimentam esse processo.

Em Ribeiro (2004), vimos a importância de investir nas tarefas teóricas e conceituais para darmos conta dos processos cada vez mais dinâmicos no território, como da urbanização difusa ${ }^{7}$ que nos exige construir, a partir de experiências teórico-empíricas, noções de cidaderegião, um dos importantes fenômenos que "[...] integram a racionalidade e a reflexividade contemporâneas, que atualizam relações técnicas e sociais de produção" (Ribeiro, 2004, p. 208).

$\mathrm{Na}$ literatura brasileira, um dos trabalhos mais conhecidos que abordam o tema cidade-região foi desenvolvido pelo professor e economista Jeroen Johannes Klin, o qual abordou a cidade-região como um espaço que assume novas atribuições no âmbito do desenvolvimento econômico em função do próprio processo de reestruturação produtiva que se acentuou no final do século passado, tomando como estudo de caso a região do Grande ABC Paulista (Santo André, São Bernardo do Campo e São Caetano do Sul). Em seu trabalho, Klink (2001) realiza a discussão central voltada à interpretação do papel das cidades-região no atual contexto da globalização, tendo o novo regionalismo como caminho da discussão.

Em seu trabalho, o conceito de cidade-região é trabalhado sob a influência da reestruturação produtiva da economia, é a luz do novo regionalismo versus o regionalismo tradicional, o que sugere desafios para 
o sistema de Governance regional frente às antigas fragilidades do tecido econômico e regional do Grande ABC Paulista (Klink, 2001).

Entre os trabalhos acadêmicos, de pós-graduação stricto sensu no país, pontuamos a dissertação de Magalhães (2008), que realiza uma reflexão teórica sobre a cidade-região, elencando as formas da cidade e de sua região a partir dos novos arranjos produtivos no território; a formação da cidade-região no Brasil e a produção do espaço na cidade-região, caracterizada pela urbanização extensiva (Monte-Mór, 1994) nas três principais áreas metropolitano-industriais brasileiras: São Paulo, Rio de Janeiro e Belo Horizonte. Para sustentar sua discussão, Magalhães (2008) utiliza como aporte os conceitos de pós-metrópole e exopolis (Soja, 2000), para entender a forma da cidade-região, e reafirma que o crescimento das metrópoles atinge, direta ou indiretamente, diversas regiões do território, o que nos mostra o surgimento desse processo a partir de uma urbanização sem fronteiras, sem respeitar as instituições oficiais do território.

O trabalho de Arrais (2008) pressupõe o estudo das relações entre os espaços regionais e a cidade, tendo como ponto de partida para análise os elementos que compõem a urbanização contemporânea e, com isso, a integração das cidades e regiões, mostrando-se como uma única unidade espacial, justificando entendê-la a partir do conceito da cidade-região (Scott et al., 2001b). Para isso, Arrais (2007) busca estudar o papel de Goiânia (GO) e sua região de influência nesse processo de integração regional, que se mostra para além dos limites políticos-administrativos oficiais das unidades federativas. No caso da capital goiana retratada por Arrais (2007), temos que considerar a proximidade e relação com a entidade político-administrativa do distrito federal, Brasília, que ganhou uma projeção na rede urbana nacional nunca vista (IBGE, 2008).

Deste modo, pelo que acompanhamos, os fenômenos urbanos de contiguidade e dispersão estão presentes na cidade-região e sua leitura deve considerar a relação destes com outros espaços inseridos na rede urbana, o que possibilita a vista da integração regional em diversas escalas (Scott et al., 2001b).

Moura (2009), ao estudar algumas obras dos autores supracitados, afirma que as cidades-região podem abranger "[...] uma relativa diversidade de configurações, podendo ser desde uma grande metrópole, um grande espaço produtivo, até uma rede de pequenas e médias cidades" (Scott et al., 2001b apud Moura, 2009, p. 59). 
Na Revista Brasileira de Geografia ${ }^{8}$, é possível listar alguns estudos em seus 222 números publicados em quase 70 anos de história, a partir de temas correlatos à geografia urbana-regional, mas também sobre a organização interna da cidade; urbanização; políticas públicas e planejamento, entre outros.

Este levantamento nos mostra uma priorização nos estudos regionais urbanos na revista, especialmente a partir da década de 1970, quando os grandes estudos regionais do IBGE (REGICs, por exemplo) começaram a ser realizados. Entretanto, é preciso destacar o crescimento das proposições teórico-metodológicas e dos artigos que versam sobre o estudo interno das cidades na revista.

Tomando como abordagem a cidade-região e a área de influência na revista, temos os primeiros estudos abordados: a cidade de Jequié (BA) e sua influência a partir da zona produtora de cacau em 1956, publicado por Santos $(1956)^{9}$ e, somente na década de 1960, com o trabalho de Corrêa (1965), sobre a área de influência da cidade de Aracajú (SE).

A partir desse levantamento, no qual apresentamos algumas produções que propõem ou utilizam a construção do conceito de cidaderegião, observamos que o interesse no país sobre o tema ainda é pouco difundido. Contudo, entendemos que estudar as relações entre os espaços regionais e a cidade demandou, nos últimos anos, a busca de novos conceitos e outras escalas de análise, e a cidade-região nos parece ser uma resposta desse novo processo de reorganização do território, ao observar os novos sentidos que a urbanização vem seguindo no Brasil nas últimas décadas (Moura, 2009; Ojima; Marandola Jr., 2012).

Por isso, torna-se importante ressaltar que entendemos o atual processo de urbanização com a formação de diversas unidades urbanoregionais no território, sendo a cidade-região uma delas, regada de fluxos e interconexões com cidades de diversos tamanhos (Moura, 2009).

\section{A cidade-região como nova expressão das cidades e/nas regiões}

Que fenômeno seria esse? A cidade-região, como aponta Lencioni (2006), é uma nova expressão da globalização na organização espacial das cidades e regiões, sendo este um novo formato e/ou uma "[...] condição, meio e produto fundamental para reprodução social dos dias atuais" (Lencioni, 2006, p. 71). 
Para grande parte dos estudiosos, a cidade-região seria uma unidade espacial polarizada e comandada por uma grande cidade (comumente relacionada a uma metrópole) que exerce influência sobre uma determinada área. Esta passa a ser definida a partir do processo de urbanização do seu entorno, tendo suas lógicas integradas através do aumento dos fluxos de pessoas, mercadorias, insumos e/ou informação de forma centrípeta em uma determinada região.

Entendemos que essas características não estão presentes apenas no topo da rede urbana brasileira, mas também na forma em que algumas cidades médias e pequenas vêm se organizando nas últimas décadas no território (Sposito, 2007). Por exemplo, quando Ojima e Marandola Jr. (2012, p. 104) colocam que:

Deslocamentos cotidianos horizontais entre cidades pequenas ou entre cidades médias, ou entre médias e pequenas, com uma pluralidade de orientações e destinos apresenta novas dinâmicas no urbano não metropolitano que ainda não estão bem delineadas, e que não passam necessariamente pelos espaços metropolitanos centrais.

O próprio limite socioespacial dessas cidades-região, que não é fácil de identificar (Lencioni, 2006), pode ser medido pela presença de outros centros de mesmo gênero. Ou seja, sua definição está ligada à sua área de influência, bem como sua relação com outras regiões. A própria relação com a metrópole regional ou nacional pode anular a formação de uma cidade-região ${ }^{10}$.

Como Parr (2005) afirma, o conceito de cidade-região vem sendo usado em diversas escalas espaciais, até mesmo para identificar territórios formados por grupos minoritários ou mesmo guetos presentes em bairros de uma cidade, porém, a sua aplicação está relacionada mais comumente à ênfase e à extensão das interações espaciais da cidade.

A cidade-região, assim como Magalhães (2008) afirma, se apresenta como um ente geográfico em plena exploração, que a torna objeto cada vez mais presente nos estudos que buscam entender os processos socioespaciais diversos que compõem a relação da cidade com a região.

Um ótimo exercício que podemos utilizar para melhor ilustrar as características de uma cidade-região é fornecido por Lencioni (2006), quando desenvolve a ideia de que os espaços se metropolizam, porém, nem todos os espaços são preenchidos pela metrópole. Em cada um desses, 
existem nuances e, para que essa leitura seja válida, é necessária uma grande extensão territorial.

O que percebemos é que o núcleo da cidade-região surge como portal de acesso às atividades econômicas presentes no território, como uma espécie de corredor de desenvolvimento regional, onde passam os fluxos de capitais, mercadorias, pessoas e informações incentivados pelo adensamento das redes e associados pela maior difusão dos modernos e rápidos sistemas de transportes e comunicação do território (Scott et al., 2001b; Lencioni, 2006).

Com isso, torna-se importante fazer um destaque sobre a confusão encontrada em alguns autores quanto à sinonímia utilizada entre as cidades globais e as cidades-região (Moura, 2009).

A cidade-região, discutida em algumas oportunidades por Scott et. al. (2001a, 2001b), é apontada como grande entrave para o planejamento urbano e regional, uma vez que existe uma dificuldade calcada na realidade, no não reconhecimento institucional dessa unidade espacial com caráter independente administrativamente, o que implica a execução de planos conjuntos, como acontece no Brasil.

Segundo Scott et al. (2001b), estes espaços são celeiros de profundas desigualdades socioespaciais distribuídas em espaços cada vez mais fragmentados e segmentados. Scott et. al. (2001a) relatam ainda que, considerando os aspectos econômicos, políticos e territoriais, as cidades-região funcionam cada vez mais como nós espaciais essenciais na economia global e, consequentemente, na organização das cidades. É possível entender que "Com essas mudanças aumentando, tornou-se cada vez mais evidente que a cidade, em sentido estrito, é uma unidade de organização social local menos apropriada ou viável do que a cidade-região ou a rede regional de cidades" (Scott et. al., 2001a, p. 11, tradução nossa). ${ }^{11}$

Considerações finais: 0 emprego da cidade-região

O conceito de cidade-região pode ser identificado em algumas escalas geográficas do espaço, como relatado por Simões e Amaral (2011, p. 566), quando enfatizam o aumento de fluxo intrarregional e a desaceleração da migração demográfica para os grandes centros urbanos, ocasionada, em parte, pela oferta de serviços e pela disponibilidade de acesso a bens de consumo mais próximos da população que vive nas 
cidades menores, fomentada, em grande parte, pela difusão das políticas de repasse de renda registrada nas últimas décadas no Brasil (Jardim, 2011). E, mesmo com seu afastamento das grandes regiões metropolitanas, estas cidades-região possuem ligações com estes centros maiores, seja por conexões aéreas, pluviais ou rodoviárias, mais comuns para esse nível de cidade.

Devemos olhar para uma cidade considerando sua região e todas as problemáticas que envolvem seu planejamento. Como já dissemos, para termos uma cidade-região, é preciso atentarmos para os limites administrativos das unidades da federação que, muitas vezes, inibem sua ação, principalmente diante da dinâmica socioeconômica deste atual momento da globalização (Arrais, 2008).

Não devemos elencar as regiões e cidades de forma desvinculada, mas sim associadas como um organismo único, enxergando as cidades nas regiões. Ademais, sabemos que a mobilidade espacial promovida pelo capital, com a multilocalização das unidades produtivas, dos negócios e investimentos à distância, vem promovendo grandes mudanças, por intermédio desse movimento de interiorização da atividade econômica e a criação de novas centralidades urbanas (Simões; Amaral, 2011), intensificando a circulação de bens, serviços e mão de obra nessas regiões.

Entendemos que esta unidade espacial se apresenta em áreas de configuração demográfica variada que, muitas vezes, não respeitam os limites administrativos do território, e que estes não coincidem com a identidade econômica e cultural do lugar, contudo, estão mais inseridos nos processos globais de mudança socioeconômica. E, ainda, não podemos nos esquecer que muitas cidades e suas regiões foram formadas a partir dos acidentes geográficos, induzindo, assim, a sua localização e desenvolvimento no território (Mumford, 1998).

Precisamos pensar nas diversas formas de mobilidade espacial, sejam definitivas, sazonais, pendulares, entre outras, em suas variadas escalas: a circulação de mercadorias entre fábricas e lojas, o deslocamento de consumidores aos centros de compras, a busca por serviços urbanos especializados, o ir e vir da escola e do trabalho para casa, a informação destinada ao consumo de massa, muitas vezes, de responsabilidade do crescente setor da publicidade e propaganda, enfim, estamos todos envolvidos nessa lógica espacial que se insere na existência e na reprodução social do atual estágio do capitalismo (Jardim, 2011). 
Para identificarmos os limites que separam a cidade-região nessa escala, torna-se importante frisar que, diferente do que é visto em alguns estudos apresentados, em que a metrópole é marcada internamente pela complexa rede de centralidades, cada vez mais representativa no interior do território (Simões; Amaral, 2011), as cidades-região denotam de uma íntima ligação com sua área de influência, ainda suscetíveis às relações de forma hierárquica na rede. Entretanto, é sabido que historicamente o conceito de cidade-região no Brasil tem sido utilizado para entender os arranjos metropolitanos, associados ao fenômeno da conurbação, reflexo da urbanização do território a partir do século XX.

Com isso, queremos dizer que os limites político-administrativos das entidades oficiais do território não definem exatamente a dimensão da cidade-região, mas podem corresponder ou apontar tais limites. Ademais, apesar de considerarmos a produção social do espaço urbano na identificação dos limites da cidade-região, a nosso ver, as relações de polarização e definição de sua hinterlândia parecem ser ainda a melhor forma de identificarmos esses espaços localizados em áreas não metropolitanas do território.

A produção do espaço da cidade-região é fruto do processo de extensão da urbanização que observamos hoje, haja vista que, além das variáveis econômicas, fundamentais para entendermos a região, a discussão pede também um apanhado social, político e cultural.

\section{Notas}

1 Para exemplificar esse fenômeno, basta atentarmos para os recentes movimentos de migrantes refugiados oriundos da Síria e do Norte da África em direção a alguns países da Europa.

2 Em um sistema urbano que compreende um conjunto de redes urbanas estruturadas e articuladas em escalas geográficas de diversas dimensões (Sposito, 2011).

3 Sobre Patrick Geddes, ver a Enciclopédia Discursiva da Cidade em: <http://www. labeurb.unicamp.br/endici/index.php?r=verbete/view\&id=40>

40 título original do livro publicado em 1915 é Cities in Evolution: an introduction to the town planning movement and to the study of civics. Esta obra foi traduzida para o português e publicada pela editora Papyrus em 1994. Uma outra obra importante de Geddes é City Development: A Study of Parks, Gardens, and Culture Institutes; a Report to the Carnegie Dunfermline Trust. Ambas as obras podem ser visualizadas pelo endereço eletrônico: <https://archive.org/>.

5 Em síntese, para Bezzi (2004), a região política seria aquela planejada, com seus limites definidos para atuação das instituições oficiais. 
6 Os textos da revista Urban Studies podem ser acessados pelo endereço eletrônico: $<$ http://usj.sagepub.com/>.

7 Na oportunidade, estudiosos vêm dando algumas denominações para explicar esse fenômeno atual da urbanização: como urbanização extensiva, explicada por Monte-Mór (1994) como um fenômeno de extensão do tecido urbano metropolitano; urbanização difusa, discutida por Sposito (2007) na leitura dos espaços urbanos não metropolitanos. A expressão mais comum encontrada na literatura brasileira sobre este processo é urbanização dispersa, em Reis Filho (2006) e Limonad (2008a, 2008b), embora esta esteja mais relacionada ao espaço da metrópole.

8 O IBGE disponibiliza todos os números da Revista Brasileira de Geografia (1939-2006) na Internet, para download, pelo endereço eletrônico: <http://www.biblioteca.ibge.gov.br>.

9 Este trabalho foi publicado de forma ampliada em um livro intitulado Cidade como centro de região: definições e métodos de avaliação da centralidade (Santos, 1959).

10 Já podemos observar que algumas importantes instituições, como a Nações Unidas, vêm considerando os dados sobre tamanhos de cidades baseados nessa unidade espacial (cidades-região) ao invés de áreas metropolitanas (Soja, 2013).

11 "As these changes have begun to run their course, it has become increasingly apparent that the city in the narrow sense is less an appropriate or viable unit of local social organization than city-regions or regional networks of cities."

\section{Referências}

ARRAIS, T. A. A região como arena política: a produção da região urbana Centro-Goiano. Goiânia: E.V., 2007.

A cidade e a região/a cidade-região: reconhecer processos, construir políticas. In: Cadernos Metrópole, São Paulo, n. 20, p. 81-91, 2008.

BEZZI, M. L. Região: uma (re)visão historiográfica - da gênese aos novos paradigmas. Santa Maria: Ed. UFSM, 2004.

CASTELLS, M. [1999]. A sociedade em rede. A era da informação: economia, sociedade e cultura. 8. ed. São Paulo: Paz e Terra, 2005.

COOMBES, M. From City-region Concept to Boundaries for Governance: The English Case. In: Urban Studies, v. 51, p. 2426-2443, ago. 2014. Disponível em: $<$ http://journals.sagepub.com/doi/abs/10.1177/0042098013493482>. Acesso em: 25 ago. 2017.

CORRÊA, R. L. Contribuição ao Estudo da Área de Influência de Aracaju. In: Revista Brasileira de Geografia, Rio de Janeiro, v. 27, n. 2, p. 233-258, abr./jun. 1965.

. [1997]. Interações espaciais. In: CASTRO, I. E. de; GOMES, P. C. da C.; CORRÊEA, R. L. (Org.). Explorações Geográficas. 2. ed. Rio de Janeiro: Bertrand Brasil, 2006. p. 279-318.

GEDDES, P. Cities in evolution an introduction to the Town planning movement and to the study of civics. London:Williams \& Norgate Henrietta Street, Covent Garden, 1915.Disponível em: <https://archive.org/details/citiesinevolutio00gedduoft $>$. Acesso em: 26 ago. 2014. 
. Cidades em evolução. São Paulo: Papirus, 1994.

HAESBAERT, R. Regional-Global: dilemas da região e da regionalização na geografia contemporânea. São Paulo: Bertrand Brasil, 2010.

HARVEY, D. [2004]. Espaços de esperança. 3. ed. São Paulo: Edições Loyola, 2009.

IBGE - Instituto Brasileiro de Geografia e Estatística. Regiões de Influência das Cidades 2007. Rio de Janeiro: IBGE, 2008.

JARDIM, A. de P. Movimentos pendulares: reflexões sobre a mobilidade pendular. In: OLIVEIRA, L. A. P. de; OLIVEIRA, A. T. R. de (Org.). Reflexões sobre os deslocamentos populacionais no Brasil. Rio de Janeiro: IBGE, 2011. p. 58-70. v. 1.

KANAI, J. M. Capital of the Amazon Rainforest: Constructing a Global City-region for Entrepreneurial Manaus. In: UrbanStudies, v. 51, p. 2387-2405, ago. 2014. Disponível em: <http://usj.sagepub.com/content/early/2013/07/12/0042098013493478>. Acesso em: set. 2014.

KLINK, J. J. A cidade-região: regionalismo e reestruturação na grande ABC paulista. Rio de Janeiro: DP\&A, 2001.

LENCIONI, S. Novos rumos e tendências da urbanização e a industrialização no estado de São Paulo. In: LIMONAD, E.; HAESBAERT, R.; MOREIRA, R. (Org.). Brasil, Século XXI - Por uma Nova Regionalização? Agentes, Processos e Escalas. São Paulo: Max Limonad, 2004. p. 68-77.

. Da cidade a sua região à cidade-região. In: SILVA, J. B. da; LIMA, L. C.; ELIAS, Denise (Org.). Panorama da Geografia Brasileira I. São Paulo: Annablume, 2006. p. 65-76.

LIMONAD, E. Urbanização dispersa: mais uma forma de expressão urbana? In: Revista Formação, UNESP, Presidente Prudente, São Paulo, n. 14, p. 31-45, 2008a.

. Espaço-tempo e urbanização: algumas considerações sobre a urbanização brasileira. In: Cidades, Presidente Prudente Grupo de Estudos Urbanos, v. 5, n. 8, p. 243-261, 2008b.

MAGALHÃES, F. N. C. Transformações socioespaciais na cidade-região em formação: a economia geopolítica do novo arranjo espacial metropolitano. 2008. 219 f. Dissertação (Mestrado em Geografia) - Programa de Pós-graduação em Geografia, Universidade Federal de Minas Gerais, Belo Horizonte, 2008.

MIN - Ministério da Integração Nacional. Política Nacional de Desenvolvimento Regional (sumário executivo). Secretaria de Programas Regionais. Brasília: SPR, 2005.

MONTE-MÓR, R. L. Urbanização extensiva e lógicas de povoamento: um olhar ambiental. In: SANTOS, M.; SOUZA, M. A. de; SILVEIRA, M. L. (Org.). Território: Globalização e Fragmentação. São Paulo: Hucitec - Anpur, 1994. p. 169-181.

MOURA, R. Arranjos urbano-regionais no Brasil: uma análise com foco em Curitiba. 2009. 242 f. Tese (Doutorado em Geografia) - Programa de PósGraduação em Geografia, Universidade Federal do Paraná, 2009. 
MUMFORD, L. [1982]. A cidade na história: suas origens, transformações e perspectivas. Tradução de Neil R. da Silva. 4. ed. São Paulo: Martins Fontes, 1998.

OJIMA, R.; MARANDOLA JR., E. Mobilidade populacional e um novo significado para as cidades: dispersão urbana e reflexiva na dinâmica regional não metropolitana. In: Revista Brasileira de Estudos Urbanos e Regionais, Rio de Janeiro, v. 14, n. 2, p. 103-116, 2012.

PARR, J. B. Perspectives on the city-region. In: Regional Studies. Londres: Routledge, 2005. p. 555-566. v. 39. Disponível em: <http://usj.sagepub.com/ content/44/2/381.short>. Acesso em: 03 mar. 2015.

REIS FILHO, N. G. Notas sobre urbanização dispersa e novas formas de tecido urbano. São Paulo: Via das Artes, 2006.

RIBEIRO, A. C. T. Regionalização: fato e ferramenta. In: LIMONAD, E.; HAESBAERT, R.; MOREIRA, R. (Org.). Brasil, século XXI - por uma nova regionalização? agentes, processos e escalas. São Paulo: Max Limonad, 2004. p. 194-212.

SANTOS, M. A cidade de Jequié e sua região. In: Revista Brasileira de Geografia, Rio de Janeiro, v. 18, n. 1, p. 71-112, jan./mar. 1956.

. Cidade como centro de região: definições e métodos de avaliação da centralidade. Salvador: Livraria Progresso Editora, 1959.

. [1996]. A natureza do espaço: técnica e tempo, razão e emoção. 4. ed. ĒDŪ̄SP: São Paulo, 2004.

. [1993]. A urbanização brasileira. 5. ed. EDUSP: São Paulo, 2005.

. [1994]. Técnica, espaço tempo: globalização e meio técnico-científicoinformacional. 5. ed. EDUSP: São Paulo, 2008.

SARMENTO, J. O evolucionismo cultural e o planejamento urbano e regional. Texto em memória aos 150 anos de nascimento do Sir Patrick Geddes (18541932). Núcleo de Investigação em Geografia e Planeamento. Universidade de Minho, 2014.

SCOTT, A. et al. Global city-regions. In: SCOTT, A. (Org.). Global City-Regions: Trends, Theory, Policy. New York: Oxford University Press, 2001a.

. Cidades-Regiões Globais. In: Espaço e Debates, São Paulo: Núcleo de Estudos Regionais e Urbanos, n. 41, p. 11-25, $2001 \mathrm{~b}$.

SIMÕES, R.; AMARAL, P. V. Interiorização e novas centralidades urbanas: uma visão prospectiva para o Brasil. In: Revista Economia, v. 12, n. 3, p. 553-579, set./ dez. 2011.

SOJA, E. Geografias pós-modernas. A reafirmação do espaço na teoria social crítica. Rio de Janeiro: Jorge Zahar Ed., 1993.

$\overline{2} \overline{0} \overline{0} \overline{.}$

. Postmetropolis. Critical studies of cities and regions. Oxford: Blackwell,

Para além de Postmetropolis. In: Revista da UFMG, Belo Horizonte, v. 20, n. 1 , p. 136-167, jan./jun. 2013. 
SPOSITO, M. E. B. Cidades médias: reestruturação das cidades e reestruturação urbana. In: SPOSITO, M. E. B. (Org.). Cidades médias: espaços em transição. São Paulo: Expressão Popular, 2007. p. 233-253.

. A produção do espaço urbano: escalas, diferenças e desigualdades socioespaciais In: CARLOS, A. F. A.; SOUZA, M. L. de; SPOSITO, M. E. B. A produção do espaço urbano: agentes e processos, escalas e desafios. São Paulo: Contexto, 2011. p. 123-145.

Josué Alencar Bezerra - Graduado e Mestre em Geografia pela Universidade Federal do Rio Grande do Norte (UFRN) e Doutor em Geografia pela Universidade Estadual do Ceará (UECE). Atualmente é Professor do Departamento de Geografia/Campus de Pau dos Ferros, da Universidade do Estado do Rio Grande do Norte (UERN).

Recebido para publicação em 12 de fevereiro de 2017 Aceito para publicação em 29 de março de 2017 